\title{
Urethrovaginal fistula repair with or without concurrent fascial sling placement: A retrospective review
}

Sarah Neu ${ }^{1}$ Jennifer Locke ${ }^{1}$; Mitchell Goldenberg ${ }^{2}$; Sender Herschorn ${ }^{1}$

${ }^{1}$ Division of Urology, Sunnybrook Health Sciences Centre, University of Toronto, Toronto, ON, Canada; ${ }^{2}$ Division of Urology, University of Toronto, Toronto, ON, Canada

Cite as: Neu S, Lock J, Goldenberg M, et al. Urethrovaginal fistula repair with or without concurrent fascial sling placement: A retrospective review. Can Urol Assoc J 2020 October 27; Epub ahead of print. http://dx.doi.org/10.5489/cuaj.6786

Published online October 27, 2020

$* * *$

\section{Abstract}

Introduction: We sought to review outcomes of urethrovaginal fistula (UVF) repair, with or without concurrent fascial sling placement.

Methods: All patients diagnosed with UVF at our center from 1988-2017 were included in this study. Patient charts were reviewed from a prospectively kept fistula database, and patient characteristics and surgical outcomes were described. Descriptive statistics were applied to compare complication rates between patients with or without fascial sling placement at the time of UVF repair.

Results: A total of 41 cases of UVF were identified, all of which underwent surgical repair. Median age at diagnosis was 49 years (interquartile range [IQR] 35-62). All patients had undergone pelvic surgery. UVF etiology was secondary to stress urinary incontinence (SUI) surgery in 17 patients (41\%) and urethral diverticulum repair in seven patients (17\%). The most common presenting symptom was continuous incontinence in 19 patients (46\%). Nineteen patients had a fascial sling placed at the time of surgery $(46 \%)$, with no significant difference in complication rates $(26 \%$ vs. $23 \%, \mathrm{p}=0.79)$. Two patients had Clavien-Dindo grade I complications $(5 \%)$ and one had a grade III complication (2\%). Four patients had long-term complications $(10 \%)$, including urinary retention, chronic pain, and urethral stricture. Two patients had UVF recurrence (5\%). Median followup after surgery was 21 months (IQR 4-72). Conclusions: UVF should be suspected in patients with continuous incontinence following a surgical procedure. Most UVF surgical repairs are successful and can be done with concurrent placement of a fascial sling. 


\section{Introduction}

Urethrovaginal fistula (UVF) is an abnormal connection between the urethra and vagina. It is a rare complication in the developed world and is most often due to iatrogenic injury from pelvic surgery. Less common etiologies include urethral instrumentation, trauma, radiation, and complications from labor. ${ }^{1,2}$ UVF has also been reported as a rare complication of antiincontinence sling procedures, including tension-free transvaginal tape (TVT) and transobturator tape placement ${ }^{3}$, likely secondary to tension necrosis of the urethra. ${ }^{4-6}$

Continuous incontinence associated with UVF may mask associated stress urinary incontinence (SUI). Simultaneous surgical correction of incontinence at the time of UVF repair to avoid a secondary surgical intervention is controversial, ${ }^{7,8}$ however small cohort studies have reported concomitant incontinence procedures with success. ${ }^{9,10}$ Literature on long term assessment and post-operative outcomes of UVF repair with or without fascial sling placement is lacking, largely due to low case volumes. In this study we review our experience with UVF repairs, with a large proportion of simultaneous fascial sling placements.

\section{Methods}

\section{Data collection and analysis}

Research ethics board approval was obtained from our institution prior to initiation of this study (REB \#330-2019). Forty-one patients diagnosed with UVF at our centre between 1988-2017 were identified and reviewed using a prospectively maintained urogenital fistula database. No patients with UVF were excluded from this study. Pre-operatively all patients were evaluated with history, physical examination, vaginal speculum exam, and cystoscopy with urethroscopy. Diagnosis of UVF was made using urethroscopy or urethrogram to identify evidence of an abnormal connection between the urethra and vagina. Select patients had CT scan and MRI imaging to gain further information on diagnosis. Surgical management of UVF is described in the section below, with 19 patients having concurrent placement of a pubovaginal sling (PVS) with autologous rectus sheath. Post-surgical follow-up was designated at one month, three months, and then arranged on a patient-by-patient basis. Prospective data collection included patient baseline characteristics, fistula etiology, presenting symptoms, fistula size, surgical intervention, intra-operative complications, hospital length of stay, fistula recurrence, postoperative and one-year complications, and long-term follow-up, where available.

Results are presented to show differences between patients who had fascial slings, and those who did not. Continuous, non-normally distributed data were presented as medians, with interquartile ranges (IQR). Complication rate was defined as a total of post-operative complications, long-term complications, and UVF recurrence. Descriptive statistics were used to compare the complication rates of patients who had a fascial sling placed at the time of UVF repair to those who did not. Descriptive statistics were also used to determine differences between patients who had a complication, and those who did not. Continuous data were analyzed 
using the Wilcoxon rank-sum test and categorical data were analyzed using the chi-square test, and the fisher exact test when expected cell counts were $<5$. All data analysis was performed using SAS University (SAS Institute Inc), with a p-value $<0.05$ considered a statistically significant difference.

\section{Surgical technique}

All UVF's were repaired by a single surgeon at a tertiary care institution. Surgical repair was done using a trans-vaginal approach, and 9/41 (22\%) women required a Martius flap. Monofilament absorbable suture 3-0 or 4-0 was used for multi-layer closure. Concomitant antiincontinence procedures with PVS placements using autologous rectus sheath were offered to patients with bothersome SUI and done in 19/41 (46\%) patients, where SUI was diagnosed with a combination of history, physical examination and urodynamics. One patient had a labial flap urethral reconstruction, and one patient with a continent diversion had a concomitant bladder neck closure. Post-operatively, patients had either placement of a suprapubic tube (SPT) with urethral foley catheter, or urethral foley catheter alone. All patients gave informed consent for surgical treatment.

\section{Results}

We identified 41 cases of UVF, all of whom underwent surgical repair. The median age at diagnosis was 49 years (IQR: 35-62). We identified 16/41 (39\%) patients as smokers. Two patients had a diagnosis of malignancy, one patient had undergone pelvic radiation, one patient had diabetes, and one patient was on chronic steroids. All patients had undergone prior pelvic surgery, with $21 / 41$ patients (51\%) having had some form of surgery to treat SUI, 10/41 (24\%) patients having had a hysterectomy, and 8/41 (20\%) patients having had a urethral diverticulum repair [Table 1]. SUI surgery included mid-urethral slings PVS, Burch colposuspension, anterior repair, and needle suspension.

The most common presenting symptom was continuous incontinence, seen in 19/41 patients $(46 \%)$. Other presenting symptoms included SUI, urgency, recurrent urinary tract infections (UTI's), difficult urethral catheterization, and difficulty voiding. The etiology of UVF was secondary to SUI surgery in 17/41 patients (41\%) (nine of who had visible mesh erosion), and urethral diverticulum repair in $7 / 41$ patients $(17 \%)$. Two patients had concomitant vesicovaginal fistulae (VVF), and one patient had concomitant VVF and uretero-vaginal fistula. 12/41 (29\%) patients had a failed surgical repair before referral to our centre. The median duration of time from fistula diagnosis to presentation at our centre was 12 months (IQR 4-40). 19/41 (46\%) patients had a PVS placement at the time of surgery. Differences in the baseline characteristics of patients who had PVS placement, vs. those who did not, can be seen in Table 1.

The median follow-up after surgery was 21 months (IQR: 4-72). The median duration of hospital stay was 3 days (IQR: 2-7). 
Intraoperative complications were rare, with one patient requiring a blood transfusion. Two patients had Clavien-Dindo Grade I complications (5\%) and one patient had a Grade III complication $(2 \%)$. The patient with a Grade III complication required reinsertion of her SPT under general anesthesia after post-operative displacement and failed reinsertion at the bed side. By one year 6/41 (15\%) patients had complications, which included urinary retention, chronic pain, urethral stricture, and UVF recurrence [Table 2]. Both cases of urinary retention resolved without intervention within three months. UVF recurrence occurred in 2/41 (5\%) patients. One patient, whose UVF occurred after cystectomy with neobladder creation for urothelial cancer, had a short-term recurrence with continuous incontinence, and was managed surgically with creation of a continent catheterizable stoma and bladder neck closure. The second patient with UVF recurrence had a complicated course with a history of multiple labial surgeries for labial cysts and urethral-cutaneous fistula. She had a small UVF recurrence after trans-vaginal repair with Martius flap with minimal symptoms. Lower urinary tract symptoms were common post-operatively, with 11/41 (27\%) patients with urgency incontinence, 10/41 (24\%) patients with SUI, 8/41 (20\%) patients with urgency, and 4/41 (10\%) patients with frequency.

Patients who had PVS placement were no more likely to have a post-operative complication ( $26 \%$ vs. $24 \%, p=.79)$. Two patients had fistula recurrence, neither of which had had PVS placement. No significant difference was found in post-operative complication rates between patients who had had prior repairs, and those undergoing a primary repair (25\% vs. $21 \%$ $p=1.0$ ), nor were there any differences found in fistula size, whether or not the patient had had prior SUI surgery or had visible mesh erosion, or was a smoker [Table 3]. Patients who had PVS placement had a $10.5 \%$ rate of post-operative SUI $(2 / 19)$ vs. a rate of $31.8 \%$ of post-operative SUI in patients who did not have slings $(7 / 22)$.

Of the 22 patients who did not have concomitant fascial sling placement, one went on to have a facial sling placed two years after surgery. This patient originally presented with fistula secondary to mesh erosion and underwent fistula repair with mesh removal. At presentation this patient had mild SUI and chose to forgo concomitant sling placement.

\section{Discussion}

In this series $98 \%$ of UVF's were secondary to iatrogenic causes, in keeping with the limited literature on UVF in the developed world. UVF as a complication of anti-incontinence synthetic sling placement has been reported, ${ }^{11-14}$ and in our cohort we found $41 \%$ of UVF's were secondary to prior SUI surgery, $53 \%$ of which were due specifically to mesh erosion. While the overall risk is low, patient's undergoing anti-incontinence sling procedures should be counselled on the risk of developing UVF. Avoiding UVF as a complication from urethral surgery includes mitigating risk factors for fistula formation where possible. In general, risk factors for genitourinary fistula include scarring from prior surgery, poor tissue healing, radiation, infection, inexperience of the surgeon, or poor surgical technique. ${ }^{12,15} \mathrm{We}$ found a high proportion of women with UVF's to be smokers (39\%), known to be associated with poor tissue healing, and 
all patients had had some form of prior pelvic surgery. Almost 30\% percent of our cohort had a failed surgical repair of UVF prior to referral to our centre. Of note, these patients did not have a higher complication rate post-operatively than those patients undergoing primary UVF repair.

Symptoms of UVF include incontinence, urgency, UTI's, and difficulty with catheterization. We found the most common presenting symptom to be continuous urinary incontinence, often associated with proximal urethral fistula or bladder neck fistula. We recommend that patients with continuous incontinence following pelvic surgery be evaluated for UVF with history, physical examination, speculum examination, cystoscopy, and urethroscopy.

The mainstay of UVF treatment is primary closure, with or without Martius flap, with a success rate of $82-95 \%$ in small cohort studies. ${ }^{7,16-18}$ This is comparable to our findings of success in $95 \%$ of patients, some of who had prior failed surgical repairs at lower volume centres. Surgical repair of urethral fistulas can be challenging, often due to a lack of local viable tissue. ${ }^{19}$ We found a 93\% success rate in repair using the trans-vaginal approach in 39 of 41 patients, with multi-layer closure with or without Martius flap interposition as needed. Transvaginal repair is preferred as it is associated with lower analgesic use, shorter hospital length of stay, and lower costs. ${ }^{20}$ For more complicated cases at the bladder neck, combined trans-vaginal trans-abdominal approach may be required.

SUI is common after UVF repair, masked pre-operatively by continuous incontinence, or as a function of sling removal, and is seen in as many as many as $50 \%$ of patients. ${ }^{21}$ Whether or not SUI can be treated at the time of UVF repair is controversial, with small cohort studies showing success. ${ }^{9,10}$ In our series, $19 / 41$ (46\%) patients had a fascial sling placed at the time of surgery, without recurrence of fistula or need for sling removal. We found no significant difference in post-operative complication rates between those who had sling placement, and those who did not. Mesh sling placements at the time of UVF repair are not recommended due to the risk of mesh erosion.

Short-term complications of UVF repair found in this study included post-operative hypertension, exterior wound break down, and SPT misplacement. Long-term complications included UVF recurrence, UTI, chronic pain, and urethral stricture. A total of 8/41 (20\%) patients had complications, with only two patients experiencing a fistula recurrence (5\%). Complication rates found in the literature range from $7-75 \%$, with a recurrence rate of 10 $33 \%$. $^{7,8,21,22}$

The main limitation of our study is that our data are from a single-surgeon, single institution cohort. The interpretation of our data is limited, due to the rarity of UVF, by the small sample size, resulting in low statistical power.

\section{Conclusions}

Although UVF is rare, it should be suspected in patients with continuous incontinence, especially following a surgical procedure. In this large series most UVF trans-vaginal surgical repairs are 
successful and can be done with concurrent placement of a fascial sling, if necessary. Secondary surgical repairs are also successful and can be repaired in the same manner as primary UVF. 


\section{References}

1. Wong, MJ, Wong, K, Rezvan, A, et al. Urogenital fistula. Female Pelvic Med Reconstr Surg 2012; 18:71-8; quiz 78.

2. Kumar M, Pandey S, Goel A, et al. Spectrum of urologic complications in obstetrics and gynecology: 13 years' experience from a tertiary referral center. Turk J Urol 2018:1-6.

3. Corcos J, Przydacz M, Campeau L, et al. CUA guideline on adult overactive bladder. Can Urol Assoc J 2017; 11:E142-73.

4. Stanford EJ and Paraiso MF. A comprehensive review of suburethral sling procedure complications. J Minim Invasive Gynecol 2008; 15:132-45.

5. Lourenco DB, Korkes F, Vetorazzo JEF et al. Functional outcomes and quality of life after transobturatory slings: Hand - made vs. commercial slings. Int Braz J Urol 2018; 44:543-9.

6. Martan A, Svabik K, Zamecnik L, et al. Surgical management of recurrent urethrovaginal fistula with a skin island flap. International Urogynecology Journal 2019; 30:839-41.

7. Lee D and Zimmern PE/ Long-term functional outcomes following non-radiated urethrovaginal fistula repair. World J Urol 2016; 34:291-6.

8. Scholler D, Brucker S, and Reisenauer C. Management of urethral lesions and urethrovaginal fistula formation following placement of a tension-free suburethral sling: Evaluation from a university continence and pelvic floor centre. Geburtshilfe Frauenheilkd 2018; 78:991-8.

9. Abdelbary AM. Martius flap and anterior vaginal wall sling for correction of urethrovaginal fistula (UVF) associated with stress urinary incontinence (SUI) after vaginal delivery. African Journal of Urology 2012; 18:175-9.

10. Chodisetti S, Boddepalli Y, and Kota MR. Concomitant repair of stress urinary incontinence with proximal urethrovaginal fistula: Our experience. Indian J Urol 2016; 32:229-31.

11. Glavind K and Larsen EH. Results and complications of tension-free vaginal tape (TVT) for surgical treatment of female stress urinary incontinence. Int Urogynecol J Pelvic Floor Dysfunct 2001; 12:370-2.

12. Morton $\mathrm{HC}$ and Hilton $\mathrm{P}$. Urethral injury associated with minimally invasive mid-urethral sling procedures for the treatment of stress urinary incontinence: A case series and systematic literature search. Bjog 2009; 116:1120-6.

13. Estevez JP, Colin P, Lucot JP, et al. Urethrovaginal fistulae resulting from sub-urethral slings for stress urinary incontinence treatment. A report of two cases and review of the literature. J Gynecol Obstet Biol Reprod (Paris) 2010; 39:151-5.

14. Reisenauer C, Janowitz J, Wallwiener D, et al. Urethrovaginal fistulae associated with tension-free vaginal tape procedures: A clinical challenge. Int Urogynecol J 2014; 25:319-22.

15. Raassen TJ, Ngongo CJ, and Mahendeka MM. Iatrogenic genitourinary fistula: An 18year retrospective review of 805 injuries. Int Urogynecol J 2014; 25:1699-706.

16. Mundy AR. Urethral substitution in women. Br J Urol 1989; 63:80-3. 
17. Elkins TE, Ghosh TS, Tagoe GA et al. Transvaginal mobilization and utilization of the anterior bladder wall to repair vesicovaginal fistulas involving the urethra. Obstet Gynecol 1992; 79:455-60.

18. Tancer ML. A report of thirty-four instances of urethrovaginal and bladder neck fistulas. Surg Gynecol Obstet 1993; 177:77-80.

19. Keettel WC, Sehring FG, deProsse CA et al. Surgical management of urethrovaginal and vesicovaginal fistulas. Am J Obstet Gynecol 1978; 131:425-31.

20. Frohmuller $\mathrm{H}$ and Hofmockel G. Transvaginal repair of vesicovaginal fistulae. Urologe A 1998; 37:102.

21. Pushkar DY, Dyakov VV, Kosko JW. et al., Management of urethrovaginal fistulas. Eur Urol 2006; 50:1000-5.

22. Rangnekar NP, Imdad Ali N, Kaul SA et al. Role of the martius procedure in the management of urinary-vaginal fistulas. J Am Coll Surg 2000; 191:259-63. 
Figures and Tables

\begin{tabular}{|c|c|c|c|}
\hline & $\begin{array}{c}\text { Patient cohort } \\
n=41\end{array}$ & $\begin{array}{c}\text { Fascial sling } \\
\text { placement } \\
n=19(46 \%)\end{array}$ & $\begin{array}{c}\text { No sling } \\
\text { placement } \\
\mathrm{n}=22(54 \%)\end{array}$ \\
\hline & n (\%) & n $(\%)$ & n $(\%)$ \\
\hline Age (years), median (IQR) & $49(35-62)$ & $49(40-62)$ & $44.5(31-62)$ \\
\hline \multicolumn{4}{|l|}{ Medical history } \\
\hline Smoker & $16(39)$ & $10(53)$ & $6(27)$ \\
\hline Malignancy & $7(17)$ & $3(16)$ & $4(18)$ \\
\hline Pelvic radiation & $2(5)$ & $1(5)$ & $1(5)$ \\
\hline Diabetes mellitus & $1(2)$ & $1(5)$ & 0 \\
\hline Chronic steroid use & $1(2)$ & $1(5)$ & 0 \\
\hline \multicolumn{4}{|l|}{$\begin{array}{l}\text { Presenting symptom leading to } \\
\text { investigations }\end{array}$} \\
\hline Continuous incontinence & $19(46)$ & $6(32)$ & $13(59)$ \\
\hline SUI & $18(44)$ & $10(53)$ & $8(36)$ \\
\hline Urgency & $7(17)$ & $3(16)$ & $4(18)$ \\
\hline Recurrent UTI & $3(7)$ & 0 & $3(14)$ \\
\hline Difficult catheterization & $3(7)$ & $1(5)$ & $2(9)$ \\
\hline Difficulty voiding & $1(2)$ & $1(5)$ & 0 \\
\hline \multicolumn{4}{|l|}{ Etiology of fistula } \\
\hline SUI surgery & $17(41)$ & $10(53)$ & $7(32)$ \\
\hline Visible mesh erosion & $9(22)$ & $4(21)$ & $5(23)$ \\
\hline Urethral diverticulum repair & $7(17)$ & $6(32)$ & $1(5)$ \\
\hline Forceps delivery & $6(15)$ & $2(11)$ & $4(18)$ \\
\hline Vaginal surgery & $4(10)$ & 0 & $4(18)$ \\
\hline Catheterization & $2(5)$ & 0 & $2(9)$ \\
\hline Cystectomy & $2(5)$ & 0 & $2(9)$ \\
\hline C-section & $1(2)$ & 0 & $1(5)$ \\
\hline
\end{tabular}


UVF repair with or without concurrent fascial sling placement

\begin{tabular}{|l|c|c|c|}
\hline \multicolumn{1}{|c|}{ Radiation } & $1(2)$ & 0 & $1(5)$ \\
\hline Unknown & $1(2)$ & $1(5)$ & 0 \\
\hline $\begin{array}{l}\text { Time to presentation (months), median } \\
\text { (IQR) }\end{array}$ & $12(4-40)$ & $14(5-48)$ & $11.5(4-30)$ \\
\hline Size of fistula (mm), median (IQR) & $5(3-10)$ & $4(3-10)$ & $8(4-10)$ \\
\hline Concomitant fistula & & & \\
\hline Vesicovaginal fistula & $2(5)$ & 0 & $2(9)$ \\
\hline Ureter-vaginal fistula & $1(2)$ & 0 & $1(5)$ \\
\hline Length of stay (days), median (IQR) & $3(2-7)$ & $2(1-4)$ & $5(3-8)$ \\
\hline Followup (months), median (IQR) & $21(4-72)$ & $21(4-56)$ & $26(4-76)$ \\
\hline
\end{tabular}

IQR: interquartile range; SUI: stress urinary incontinence; UTI: urinary tract infection.

\section{Table 2. Complications following surgical management of UVF}

\begin{tabular}{|l|c|c|c|}
\hline & $\begin{array}{c}\text { Total cohort } \\
\mathbf{n = 4 1}\end{array}$ & $\begin{array}{c}\text { Fascial sling } \\
\text { placement } \\
\mathbf{n = 1 9} \mathbf{4 6 \% )}\end{array}$ & $\begin{array}{c}\text { No sling } \\
\text { placement } \\
\mathbf{n = 2 2}(\mathbf{5 4 \%})\end{array}$ \\
\hline Postoperative complications & & & \\
\hline Clavien-Dindo grade & 2 & 2 & 0 \\
\hline $\begin{array}{l}\text { I: Hypertension requiring medical treatment; } \\
\text { superficial labial wound breakdown - self- } \\
\text { resolving }\end{array}$ & 1 & $\mathbf{3}$ & 0 \\
\hline $\begin{array}{l}\text { IIIb: Suprapubic tube placement in OR } \\
\text { Total }\end{array}$ & & $\mathbf{3}$ & $\mathbf{0}$ \\
\hline Long-term complications & 2 & 2 & 0 \\
\hline Urinary retention & 1 & 0 & 1 \\
\hline Chronic pain & 2 & 0 & 1 \\
\hline Urethral stricture & $\mathbf{6}$ & $\mathbf{2}$ & 2 \\
\hline Fistula recurrence & & $\mathbf{4}$ \\
\hline Total & & & \\
\hline
\end{tabular}

OR: operating room. 
UVF repair with or without concurrent fascial sling placement

\begin{tabular}{|l|c|c|c|}
\hline Variable & $\begin{array}{c}\text { Complication n=9 } \\
\mathbf{n}, \mathbf{( \% )}\end{array}$ & $\begin{array}{c}\text { No complication } \\
\mathbf{n = 3 2} \\
\mathbf{n}, \mathbf{( \% )}\end{array}$ & $\mathbf{p}$ \\
\hline $\begin{array}{l}\text { Fascial sling placement at time of } \\
\text { surgery }\end{array}$ & $5(56)$ & $14(44)$ & 0.71 \\
\hline Previous surgical repair & $3(33)$ & $9(28)$ & 1.0 \\
\hline Size of fistula $>5 \mathrm{~mm}$ & $3(33)$ & $14(44)$ & 0.71 \\
\hline Prior SUI surgery & $4(44)$ & $17(53)$ & 0.72 \\
\hline Visible mesh erosion & $1(11)$ & $8(25)$ & 0.73 \\
\hline Smoker & $3(33)$ & $13(41)$ & 1.0 \\
\hline
\end{tabular}

SUI: stress urinary incontinence; UVF: urethrovaginal fistula. 